\title{
Metformin Toxicity in Acute Kidney Injury - A Rare Cause of Severe Lactic Acidosis
}

\author{
Ajmal MS*, Vinod S and Yan J \\ Department of Nephrology, Baylor College of Medicine, Houston TX, USA
}

\begin{abstract}
Metformin a biguanide derivative is the preferred initial pharmacologic agent for the treatment of type 2 diabetes mellitus per current guidelines of the American Diabetes Association. It is prescribed to an estimated 120 million people worldwide. Type B lactic acidosis is a reported but rare side effect of Metformin use. Serum Metformin level is not routinely monitored or available in most hospitals, but it can be a useful test to confirm the diagnosis and guide future use of Metformin in at risk patients. We present a case of a 78-year old African American diabetic female on prescribed dose of Metformin with no history of kidney disease who presented with acute encephalopathy and hemodynamic instability. Her laboratory data showed acute kidney injury (AKI) with severe lactic acidosis (LA). She required large amount of intravenous bicarbonate infusions and urgent initiation of Continuous Veno-Venous Hemodialysis (CVVHD) due to severe refractory metabolic acidosis. Her serum Metformin level sent 12 hours after initiation of CVVHD was still critically elevated at $19 \mathrm{mcg} / \mathrm{ml}$. Her acidosis and AKI started to resolve after 48 hours of CVVHD with resolution of encephalopathy as well. Her renal function returned to baseline and she was eventually discharged home, but Metformin was not resumed back.
\end{abstract}

Keywords: Metformin; Lactic acidosis; Acute kidney injury

\section{Introduction}

Metformin a biguanide derivative is widely used for the treatment of type 2 diabetes mellitus. It can rarely cause type $\mathrm{B}$ lactic acidosis due to accumulation of Metformin in the body due to decreased renal clearance. Early recognition and knowledge of the risk factors that precipitate Metformin-associated lactic acidosis (MALA) can help avoid this life-threatening condition. Serum Metformin level can be a useful tool to confirm the etiology of unexplained lactic acidosis and will guide future use of this medication by the patient.

\section{Case Report}

78-year old African American female with Past medical history of diabetes mellitus type 2, hypertension and colonic diverticulosis presented to our Emergency room (ER) with altered mental status, decreased oral intake and hypoglycemia at home. She was evaluated in another ER eight days ago for abdominal pain and received a CAT scan of abdomen/pelvis with intravenous (IV) contrast which showed minimal sigmoid diverticulitis. She had a serum Creatinine of 1 milligram/deciliter $(\mathrm{mg} / \mathrm{dl})$ with an estimated glomerular filtration rate (eGFR) of $63 \mathrm{ml} / \mathrm{min} / 1.73 \mathrm{~m}^{2}$ at that time. She was discharge home on oral Ciprofloxacin and Metronidazole. Two days later, she presented to our ER for abdominal pain and another CAT scan of abdomen/pelvis with IV contrast was performed which showed cholelithiasis with minimally distended gall bladder. She was admitted to the hospital and a hepatobiliary scan was performed which did not show acute cholecystitis. Patient subsequently refused elective cholecystectomy and was discharged home. Daughter reported that patient had decreased oral intake but was taking her prescription medications. Pertinent home medications include Metformin $1000 \mathrm{mg}$ twice daily, Glimepiride $4 \mathrm{mg}$ daily, Benazepril $20 \mathrm{mg}$ daily, Lasix $20 \mathrm{mg}$ daily and Insulin Detemir 18 units in the morning and 14 units at night .

On current presentation, she was lethargic and difficult to arouse. She was afebrile, blood pressure $94 / 44 \mathrm{~mm} \mathrm{Hg}$, Heart rate $61 / \mathrm{min}$, O2 saturation $99 \%$ Room air and respiratory rate was 18/minute. Laboratory data showed mild leukocytosis (White blood cells 11,700), elevated lactate level (>13.3), acute kidney injury (Serum Creatinine
$12.52 \mathrm{mg} / \mathrm{dl}$ and Blood urea nitrogen $99 \mathrm{mg} / \mathrm{dl}$ ), metabolic acidosis ( Serum bicarbonate 7 milliequivalent/liter (meq/l), Anion gap 27 and $\mathrm{PH}$ 7.14) and hyperkalemia (K $6.0 \mathrm{meq} / \mathrm{l})$. Repeat labs showed worsening acidosis with PH 7.01 and serum Bicarbonate $5 \mathrm{meq} / \mathrm{l}$. She had no urine output even after placement of Foley catheter. She received 3.4 Liters of Normal saline intravenously (IV) in the ER and received IV Cefepime and Metronidazole empirically. She received multiple IV pushes of sodium bicarbonate amounting to $275 \mathrm{meq}$ of bicarbonate and due to refractory lactic acidosis, she was started on Continuous Veno-Venous Hemodialysis (CVVHD). A serum Metformin level was sent almost 12 hours after initiation of CVVHD due to lack of local availability.

She remained hypotensive and required Norepinephrine and Vasopressin infusions. In the ICU, she required sodium bicarbonate $8.4 \%(1 \mathrm{meq} / \mathrm{ml})$ infusions in addition to the CVVHD. A total of 4 IV infusions were given amounting to $600 \mathrm{meq}$ Sodium bicarbonate. During next 24 hours, her $\mathrm{PH}$ improved to 7.28 but serum bicarbonate was still low at $9 \mathrm{meq} / \mathrm{l}$. Her serum Sodium increased to $150 \mathrm{meq} / \mathrm{liter}$ (meq/l) from a level of $131 \mathrm{meq} / \mathrm{l}$ at initial presentation due to the hypertonic sodium bicarbonate infusions. She was then transitioned to hypotonic IV fluids. It took another 24 hours of CVVHD before her serum bicarbonate improved to $24 \mathrm{meq} / \mathrm{l}$ and her anion gap closed. Her hemodynamics improved, urine output recovered, and her mental status returned to baseline. Her urine microscopy showed few granular casts suggestive of acute tubular necrosis (ATN). She had significant post ATN diuresis. She was eventually discharged home with a serum Creatinine of $1 \mathrm{mg} / \mathrm{dl}$ and eGFR $63 \mathrm{ml} / \mathrm{min} / 1.73 \mathrm{~m}^{2}$ on the day of discharge.

*Corresponding author: Ajmal MS, Department of Nephrology, Baylor College of Medicine, Houston TX, USA, Tel: +17163351847; E-mail: Muhammad.ajmal@bcm.edu

Received: June 10, 2019; Accepted: June 24, 2019; Published: June 29, 2018

Citation: Ajmal MS, Vinod S, Yan J (2019) Metformin Toxicity in Acute Kidney Injury - A Rare Cause of Severe Lactic Acidosis. J Nephrol Ther 9: 332.

Copyright: ( 2018 Ajmal MS, et al. This is an open-access article distributed under the terms of the Creative Commons Attribution License, which permits unrestricted use, distribution, and reproduction in any medium, provided the original author and source are credited. 
A serum Metformin level reported after her discharge showed a very high level of $19 \mathrm{microgram} / \mathrm{milliliter}(\mathrm{mcg} / \mathrm{ml})$ whereas the therapeutic range is $1-2 \mathrm{mcg} / \mathrm{ml}$ (Figure 1 ).

It took 48 hours of CVVHD before serum Lactate and Bicarbonate returned to normal range.

\section{Discussion}

Metformin a biguanide derivative is the preferred initial pharmacologic agent for the treatment of type 2 Diabetes Mellitus per current guidelines of the American Diabetes Association [1]. It is prescribed to an estimated 120 million people worldwide [2] Metformin decreases blood glucose levels by decreasing hepatic glucose production (gluconeogenesis), decreasing the intestinal absorption of glucose, and increasing insulin sensitivity by increasing peripheral glucose uptake and utilization. Metformin inhibits mitochondrial complex I activity, and it has been generally postulated that its potent antidiabetic effects occur through this mechanism [3,4]. Metformin is eliminated primarily unchanged by the kidneys by both filtration and active tubular secretion [5]. Renal clearance of Metformin decreases in proportion to decreasing estimated glomerular filtration rate (GFR). One of the most important known risk factors for elevated Metformin concentration is the inability to clear the drug efficiently due to renal impairment [6].

Most common side effects of Metformin are gastrointestinal symptoms such as nausea, vomiting and diarrhea. Type B lactic acidosis is a reported but rare side effect of Metformin use. Metformin decreases liver uptake of lactate, thereby increasing lactate blood levels which may increase the risk of lactic acidosis. Almost all reported cases of Metformin-associated lactic acidosis have occurred in patients with underlying chronic kidney disease. A Cochrane review of 347 comparative trials and cohort studies revealed no cases of fatal or nonfatal lactic acidosis in 70,490 patient-years of Metformin use or in 55,451 patients-years in the non-Metformin group [7]. Results of a matched Case-Control study showed that Metformin may be associated with lactic acidosis in AKI but not in patients with type 2 diabetes without AKI. Variables significantly associated with lactic acidosis in patients who presented an AKI were shock, acute respiratory failure, and injection of iodinated contrast media, severe anemia, hepatocellular dysfunction, acute decompensated heart failure, sepsis, and Metformin. Angiotensin converting enzyme inhibitors, Angiotensin receptor blockers, NSAID, diuretics, and iodinated contrast media has the potential to cause lactic acidosis indirectly by AKI and Anti-retroviral drugs cause by direct action on mitochondrial activity [8]

We present a unique case where an elderly female with no preexisting kidney disease and taking appropriately prescribed dose of Metformin develop severe acute kidney injury with lactic acidosis due to repeated IV contrast exposure and volume depletion in the span of 1 week. Metformin itself is not nephrotoxic but can accumulate in setting of acute or chronically low glomerular filtration rate and lead to type B lactic acidosis. This require caution especially in elderly patient on Metformin who may have another etiology leading to acute kidney injury but concurrent use of Metformin in this setting can lead to severe lactic acidosis and life-threatening illness. Serum Metformin level measurement is not routinely available in hospitals but can be sent out to specialized laboratories and is a good resource to confirm diagnosis of metformin induced lactic acidosis and help guide future dosing of Metformin or substitution to another drug class. In a retrospective review of 66 patients on chronic metformin therapy with lactic acidosis requiring hospital admission, plasma Metformin level showed a statistically significant correlation with plasma Creatinine and lactate levels. However, the mean plasma Metformin and lactate levels were not different in deceased or surviving patient [9].

Serum Metformin has large volume of distribution and minimally protein bound which makes it dialyzable. Initial treatment of Metformin-associated lactic acidosis (MALA) is supportive including oxygen, ventilator support if needed, fluid administration and vasopressors if needed. Hemodialysis has been effectively used in the removal of MALA. Per Extracorporeal treatments in Metformin poisoning workgroup, indications for extracorporeal treatment include lactate concentration greater than $20 \mathrm{mmol} / \mathrm{L}, \mathrm{pH}$ less than or equal to 7.0 , shock, failure of standard supportive measures, and decreased level of consciousness. Intermittent hemodialysis is preferred initially, but continuous renal replacement therapies may be considered if hemodialysis is unavailable [10]. The role of exogenous bicarbonate therapy in patients with lactic acidosis is controversial. Most, but not all, experts believe that it is appropriate to use bicarbonate in acutely

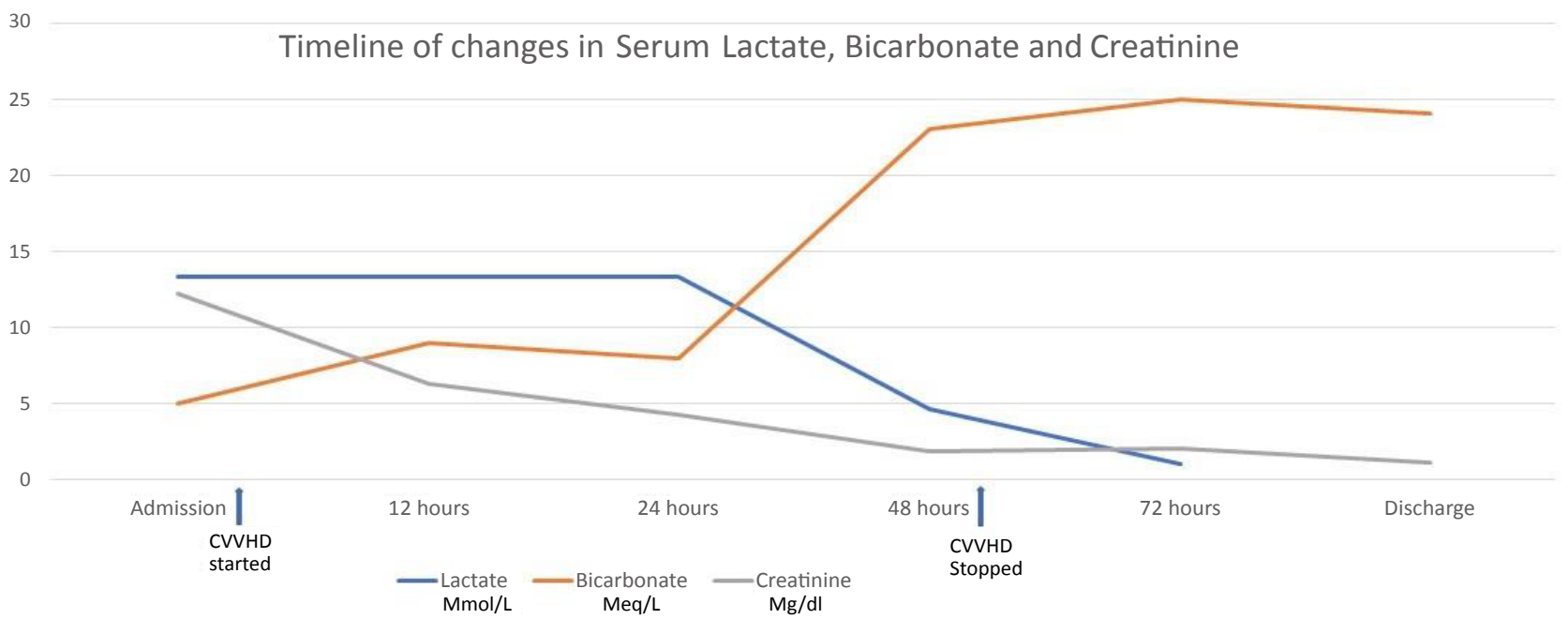

Figure 1: Timeline of changes in serum Lactate, Bicarbonate and Creatinine since admission. 
ill patients with profound lactic acidosis and acidemia (arterial pH less than 7.1) [11,12]. Compared to other forms of lactic acidosis, MALA was associated with a lower $\mathrm{PH}$ and a higher bicarbonate concentration. Overall, survival was better in MALA as compared to other forms of lactic acidosis [13].

\section{Disclosure}

None of the authors have any disclosures or conflict of interest.

\section{References}

1. Pharmacologic Approaches to Glycemic Treatment: Standards of Medical Care in Diabetes (2019) American Diabetes Association, Diabetes Care 42: S90-102.

2. Viollet B, Guigas B, Garcia NS, Leclerc J, Foretz M, et al. (2012) Cellular and molecular mechanisms of metformin: an overview. Clin Sci (Lond) 122: 253-70.

3. Rena G, Hardie DG, Pearson ER (2017) The mechanisms of action of metformin. Diabetologia 60: 1577-1585.

4. Rena G, Pearson ER, Sakamoto K (2013) Molecular mechanism of action of metformin: old or new insights? Diabetologia 56: 1898-906.

5. Lipska KJ, Bailey CJ, Inzucchi SE (2011) Use of metformin in the setting of mild-to-moderate renal insufficiency. Diabetes Care 34: 1431-37.

6. Sambol NC, Chiang J, Lin ET, Goodman AM, Liu CY, et al. (1995) Kidney function and age are both predictors of pharmacokinetics of metformin. J Clin Pharmacol 35: 1094-1102.
7. Salpeter SR, Greyber E, Pasternak GA, Salpeter EE (2010) Risk of fatal and nonfatal lactic acidosis with metformin use in type 2 diabetes mellitus. Cochrane Database Syst Rev14: CD002967.

8. Lepelley M, Giai J, Yahiaoui N, Chanoine S, Villier C (2016) Lactic Acidosis in Diabetic Population: Is Metformin Implicated? Results of a Matched CaseControl Study Performed on the Type 2 Diabetes Population of Grenoble Hospital University. J Diabetes Res 2016: 3545914.

9. Vecchio S, Giampreti A, Petrolini VM, Lonati D, Protti A, et al. (2014) Metformin accumulation: lactic acidosis and high plasmatic metformin levels in a retrospective case series of 66 patients on chronic therapy. Clin Toxicol (Phila) 52: 129-135.

10. Calello DP, Liu KD, Wiegand TJ, Roberts DM, Lavergne V, et al. (2015) Extracorporeal Treatments in Poisoning Workgroup. Extracorporeal Treatment for Metformin Poisoning: Systematic Review and Recommendations From the Extracorporeal Treatments in Poisoning Workgroup. Crit Care Med 43: 17161730.

11. Kraut JA, Kurtz I (2001) Use of base in the treatment of severe acidemic states Am J Kidney Dis 38: 703-727.

12. Mathieu D, Neviere R, Billard V, Fleyfel M, Wattel F (1991) Effects of bicarbonate therapy on hemodynamics and tissue oxygenation in patients with lactic acidosis: a prospective, controlled clinical study. Crit Care Med 19: 1352 1356.

13. Friesecke S, Abel P, Roser M, Felix SB, Runge S (2010) Outcome of severe lactic acidosis associated with metformin accumulation. Crit Care 14: 226. 